\title{
PELAKSANAAN SUPERVISI PENDIDIKAN DALAM PENINGKATAN PROFESIONALISME GURU DI MAN 2 PANGANDARAN
}

\author{
Dadah Jubaedah ${ }^{1}$, Deti Mulyanti ${ }^{2 .}$ \\ ${ }^{1,2}$ Universitas Sangga Buana \\ ${ }^{1}$ korespondensi : dadahjubaedah22.man2pnd@gmail.com
}

\begin{abstract}
The purpose of the study was to determine the effect of the implementation of teacher supervision in increasing teacher professionalism at MAN 2 Pangandaran, the object of the study was the teacher of MAN 2 Pangandaran. This type of research is qualitative with a field research approach. The results of the study show that the implementation of teacher supervision at MAN 2 Pangandaran includes three stages, namely; preparation stage (programming and instrument preparation), implementation stage (direct and indirect implementation), and reporting stage. The implementation of teacher supervision at MAN 2 Pangandaran has not had an effect on increasing teacher professionalism there. This is caused by the leadership role of supervisors who are less creative in making efficient and innovative supervision programs.
\end{abstract}

Keyword: Education supervision, preparation, implementation and reporting, teacher professionalism

\section{ABSTRAK}

Tujuan dari penelitian adalah mengetahui pengaruh pelaksanaan supervisi guru dalam peningkatan profesionalisme guru di MAN 2 Pangandaran, yang menjadi objek dalam penelitian adalah guru MAN 2 Pangandaran. Jenis penelitiannya kualitatif, pendekatan penelitian lapangan. Hasil dari penelitian menunjukkan pelaksanaan supervisi guru di di MAN 2 Pangandaran meliputi tiga tahap yaitu; tahap persiapan (penyusunan program dan penyiapan instrument), tahap pelaksanaan (pelaksanaan secara langsung dan tidak langsung), dan tahap pelaporan. Pelaksanaan supervisi guru di MAN 2 Pangandaran belum memberikan pengaruh untuk meningkatkan guru yang berprofesional. Peran Pemimpin yang mendukung untuk membuat program supervisi pendidikan yang kreatif, inovatif, efektif dan efisien.

Kata Kunci: Supervisi pendidikan, persiapan, pelakasanaan dan pelaporan, profesionalisme guru

\section{PENDAHULUAN}

Pendidikan sebagai suatu sistem terdiri dari beberapa komponen. Beberapa diantaranya adalah peserta didik, pendidik /guru dan pengawasan mutu. Sebagai salah satu komponen yang berperan penting adalah guru. Guru memerlukan layanan supervisi yang dilakukan oleh kepala sekolah atau pengawasan yang biasa disebut dengan supervisor. Untuk dapat menjalankan tugas sebagai supervisor diperlukan kelebihan yang dapat memahami permasalahan dalam peningkatan mutu pendidikan.
Supervisor berperan dalam membina peningkatan mutu pendidikan yaitu usaha untuk menciptakan kondisi pembelajaran yang lebih baik. Mutu kelembagaan akan berkembang baik jika supervisi diarahkan pada kinerja dan pengawasan mutu pendidikan. Supervisi meningkakan kualitas pembelajaran sehingga diperoleh pembelajaran yang efisien dan efektif. Menanggulangi hambatan atau problem dalam kegiatan pembelajaran sehingga kegiatan supervisi yang dilakukan bisa meningkatkatkan profesionalisme guru. 
Peningkatan profesionalisme guru dapat berkorelasi positif pada kualitas pembelajaran. Hal ini sejalan dengan perkembangan supervisi yang lebih menekankan kepada upaya Pengembangan Keprofesionalan Berkelanjutan (PKB). Perkembangan ilmu pengetahuan dan teknologi yang begitu pesat, perlu disikapi dengan inovasi guru untuk meningkatkan kualitas pembelajaran. Selain itu, guru perlu mempelajari sehingga menemukan problem dalam pembelajaran. Dalam hal ini diperlukan fasilitator yaitu supervisor untuk mengembangkan keprofesionalan tersebut. Motivasi guru perlu selalu dipupuk untuk selalu meningkatkan keprofesionalannya.

Supervisor berkewajiban melaksanakan pembinaan administrasi dan supervisi terhadap pembelajaran. Sistem proses pembelajaran yang diciptakan guru diduga berpengaruh terhadap kualitas pembelajaran siswa. Dengan demikian, peran supervisor yang dilaksanakan oleh pengawas dan kepala sekolah harus dilaksanakan secara secara berkesinambungan agar dapat meningkatkan mutu pembelajaran.

Terdapat beberapa problem di lapangan, jika supervisi dilaksanakan. Pengawas atau kepala sekolah yang melakukan supervisi, samasama menimbulkan problem. Seperti masih negatifnya pandangan guru terhadap supervisi, yaitu asumsi bahwa guru merasa tertekan dan kurang bebas dalam mengemukakan ide-idenya. Sikap supervisor yang kurang melibatkan guru dalam proses perencanannya, merasa sebagai penguasa dalam memutuskan supervisi, dapat berpengaruh terhadap efektivitas supervisi. dari guru karena jabatannya. Senioritas guru yang merasa bahwa supervisi sebagai hal yang tidak bermakna dan merasa kalau profesionalisme dan pengalamannya lebih mendalam dibanding supervisor. Hal tersebut menjadi problem bagi supervisor untuk melakukan pengawasan karena tidak mendapat respon dari guru tersebut. Padahal seharusnya guru antusias untuk disupervisi agar dapat meningkatkan keprofesionalannya. Oleh karena itu, dalam makalah ini penulis akan menyampaikan bagaimana alternatif dalam memecahkan masalah dalam pelaksanaan supervisi pendidikan terkait dengan sumber daya guru tersebut.

Sebagai salah satu komponen sumber daya manusia yang harus terus ditingkatkan profesionalismenya, guru berperan besar dalam menentukan kualitas pendidikan. Perubahan ilmu pengetahuan dan teknologi yang cepat, menuntut kreativitas para guru supaya bisa menempatkan diri terhadap kemajuan di bidang pendidikan itu.

Meningkatnya profesionalisme guru dipengaruhi oleh beberapa faktor seperti keefektifan kepemimpinan kepala sekolah, tanggungjawab guru dan tenaga kependidikan, proses pembelajaran yang bermakna, relevansi ruang lingkup pelajaran, kejelasan tujuan sekolah, lingkungan sekolah yang nyaman, dan evaluasi diri terhadap kelebihan dan kekurangan lembaga.

Rumusan permasalahannya adalah Bagaimana pelaksanaan supervisi pendidikan guru di MAN 2 Pangandaran? (2) Bagaimana profesionalisme guru di MAN 2 
Pangandaran? (3) Bagaimana pengaruh pelaksanaan supervisi pendidikan guru untuk meningkatkan profesionalisme guru di MAN 2 Pangandaran?

Tujuannya untuk mengetahui pelaksanaan supervisi guru di MAN 2 Pangandaran? (2)

Mengetahui profesionalisme guru di MAN 2

Pangandaran? (3) Mengetahui pengaruh pelaksanaan supervisi pendidikan guru untuk meningkatkan profesionalisme guru di MAN 2 Pangandaran?

\section{TINJAUAN PUSTAKA}

\section{Supervisi Pendidikan}

Supervisi adalah suatu aktivitas pembinaan yang direncanakan untuk membantu para guru dan pegawai sekolah lainnya dalam melakukan pekerjaan mereka secara efektif [1]. Dari beberapa pengertian tersebut dapat disimpulkan bahwa supervisi adalah kegiatan yang direncanakan yang dilakukan oleh pimpinan dengan tujuan untuk membantu pegawai agar pekerjaannya lebih berkualitas [2].

Namun kenyataan di sekolah, supervisi masih dilaksanakan kurang terarah. Tidak ada kejelasan tentang aspek mana yang akan dijadikan sebagai fokus atau apa yang akan yang menjadi priorotas perhatian. Hal ini berdampak pada pemberian tanggapan langsung kurang terarah kepada hal sebenarnya yang diperlukan oleh guru. Di pihak lain, pemahaman guru terhadap manfaat supervisi masih kurang. Salah satu penyebabnya adalah tidak adanya musyawarah antara supervisor dengan guru yang akan disupervisi. Padahal sebenarnya supervisi akan lebih efisien dan efektif jika guru sejak tahap perencanaan dilibatkan dalam musyawarah. Guru akan memahami dampak positif supervisi baginya secara pribadi ataupun bagi siswa atau lembaganya. Supervisi adalah solusi yang tepat untuk mengatasi problem atau permasalahan yang terjadi dalam pembelajaran.

Pengawas dan kepala sekolah sebagai supervisor harus faham juga sanggup melaksanakan supervisi. Guru berperan begitu berarti diawali pada merencanakan kemudian menganalisis hasilnya. Peningkatkan kualitas guru salah satunya adalah melalui supervisi proses pembelajaran. Jika guru proaktif disupervisi, maka akan tercipta kemajuan dan pengembangan pembelajaran. Dimana guru dapat menciptakan kondisi pembelajaran yang optimal. Supervisi yang dilaksanakan tidak lain adalah bentuk bantuan bimbingan terhadap guru. Diinginkan, dampaknya bisa dilihat pada hasil belajar siswa.

Jadi supaya peenyelenggaraannya dapat berjalan maksimal, pengawas dan kepala sekolah sebagai supervisor harus melibatkan guru pada perencanaan pelaksanaan supervisi agar guru dapat mengetahui manfaat supervisi baginya, dan juga gaya supervisor yang tidak otoriter sehingga dengan begitu guru tidak memandang negatif supervisi dan semakin termotivasi dalam meningkatkan keprofesionalannya, dengan begitu dapat berkembangnya pembelajaran tercapainya tujuan pendidikan. 


\section{Profesionalisme Guru}

Istilah kompetensi atau competence adalah kemahiran atau kecakapan. Maksudnya adalah kecakapan guru dalam pengelolaan proses pembelajaran yang dilakukan dengan penuh tanggung jawab mulai dari perencanaan, pelaksanaan, evaluasi, dan tindaklanjutnya.

Menurut istilah lain, profesionalisme bermula dari kata profesi. Yaitu seseorang yang menempati posisi atau yang mempunyai tugas dimana tugas tersebut menuntutnya untuk bekerja dengan pertanggungjawaban tinggi, ahli, serta terus menerus menekuni bidangnya itu. Profesionalisme mengarah kepada orang yang melaksanakan keahliannya atau kecakapannya dalam melaksanakan bidangnya. Profesionalisme guru berarti bahwa melaksanakan kecakapan di bidang keahliannya yaitu melaksanakan pembelajaran yang meningkatkan mutu pembelajaran.

Standar Nasional Pendidikan Pasal 28 ayat (3) butir c menjelaskan bahwa "kompetensi profesional adalah kemampuan dalam menguasai materi pembelajaran secara luas dan mendalam agar peserta didik dapat memenuhi standar nasional pendidikan. Mampu dalam memanfaatkan teknologi informasi dan komunikasi dalam mengembangkan diri”.

Kompetensi profesional adalah kemampuan yang harus dimiliki oleh guru [3]. Guru harus memiliki kompetensi profesional yaitu mampu merancang, merealisasikan, mengawasi, menguji dan meningkatkan mutu pembelajaran. Jika kompetensi profesional adalah kemampuan yang harus dimilliki oleh guru dalam pemilihan materi dan metode pembelajaran untuk diaplikasikan dalam proses pembelajaran [4].

"Kompetensi guru memiliki 4 macam diantaranya kompetensi pedagogik, kompetensi kepribadian, kompetensi sosial, dan kompetensi profesional". Jadi kompetensi profesional adalah kecakapnn guru dalam bidang penguasaan materi juga metode pembelajaran untuk diterapkan dalam pelaksanaan pembelajaran. [4]

Kompetensi guru sangat perlu diperhatikan karena kompetensi berguna dalam meningkatkan dan memajukan profesionalisme guru dan untuk mencapai tujuan pendikikan. Untuk menjadi guru profesional guru dituntut memiliki hal-hal "mempunyai kemampuan dalam mendidik, keahlian yang terintegrasi, sehat jasmani maupun rohani, mahir dalam mengajar, dan berpengalaman dan pengetahuan yang luas". [5]

Guru profesional harus mampu mengembangkan

kepribadiannya, berkomunikasi dengan baik, melaksanakan administrasi sekolah, melaksanakan pembelajaran dan mengevaluasi hasilnya. Guru yang profesional harus memiliki tanggungjawab tinggi terhadap pendidikan siswa. Baiknya mutu pembelajaran akan dapat meningkatkan mutu pendidikan.

Guru profesional memiliki tugas secara khusus meliputi: Pertama, memiliki rasa cinta kasih dan tulus ikhlas dalam mengajar. Melalui proses pembelajaran guru akan memiliki rasa cinta dan kasih sayang dan 
siswa akan merasa nyaman belajar bersama guru. Kedua, guru profesional wajib mempunyai rasa tanggungjawab, semangat dan motivasi tinggi untuk mengabdikan ilmu yang dimilikinya hanya karena Allah SWT. Ketiga, guru harus memiliki akhlak dan budi pekerti luhur. Guru harus terus menerus belajar supaya kemampuannya makin berkembang.

Kompetensi profesioal guru adalah keahlian dan kompetensi guru dalam mengelola pembelajaran mencakup: perencanaan, pelaksanaan, dan evaluasi pembelajaran sesuai dengan bidang yang dimilikinya. Kompetensi profesional yang harus dimiliki oleh seorang guru adalah sebagai berikut:

1) Penguasaan materi dalam pembelajaran, yang meliputi konsep, struktur dan metoda yang di dukung dengan pelajaran yang diampunya.

2) Kemampuan dalam menerapkan konsepkonsep keilmuan dalam kehidupan sehari-hari

3) Pengembangan materi pembelajaran secara kreatif dan inovatif

4) Melakukan kegiatan reflektif yang berkelanjutan yang bertujuan dalam pengembangan keprofesionalisme

5) Memanfaatkan TIK untuk mengembangkan pembelajarannya seperti internet dan komputer.

Ruang lingkup kompetensi profesional guru terdiri atas:

1) Mampu memahami dan mengimplementasi dan mengaktualisasikan landasan-landasan kependidikan seperti landasan psikologis, filosofis, dan sosiologis

2) Mampu mengaktualisasikan teori-teori pembelajaran dalam proses pembelajaran

3) Mampu mengembangkan materi-materi pelajaran

4) Mampu menyesuaikan metode pembelajaran dengan materi yang sedang dibahas

5) Terampil memilih alat dan media pembelajaran

6) Terampil mengatur waktu dalam pelaksanaan program pembelajaran

7) Mampu menilai dan mengevaluasi hasil belajar dari peserta didik

8) Kemampuan untuk membentuk kepribadian peserta didik.

Guru dituntuk untuk memiliki kemampuan dalam memilih, memilah dan melakukan pengelompokkan materi pembelajaran yang akan disampaikan kepada peserta didik. Kemudian dilakukan penyesuaian.

Kompetensi tersebut juga mendorong guru untuk terampil dalam menguasai materi pembelajaran yang disampaikan kepada peserta didik. Sampai kepada langkahlangkah yang harus dilaksanakan dalam mendalami pelajaran ampunnya. Apabila guru tidak memiliki keahlian dalam bidangnya, maka dalam melaksanakan pekerjaannya akan terhambat. Guru harus memiliki keahlian di bidang studi yang di ampunya. Keahlian dan kemampuan adalah persyaratan yang mutlak dalam peningkatan kualitas pendidikan di sekolah. Guru akan mudah melaksanakan pembelajaran sehingga pembelajaran berlangsung efisien dan efektif. 


\section{METODE}

Jenis penelitian ini adalah penelitian kualitatif.

Penelitian ini dilakukan di MAN 2

Pangandaran. Penuli memilih lokasi di MAN

2 Pangandaran dikarenakan terjadi di MAN 2

Pangandaran daya saing dan kualitas pendidikannya masih rendah dibandingkan dengan kualitas pendidikan SMA yang kemudian berdampak pada timbulnya kesan negatif masyarakat sekitar.

Adapun untuk empirik penulis menggunakan beberapa metode yaitu:

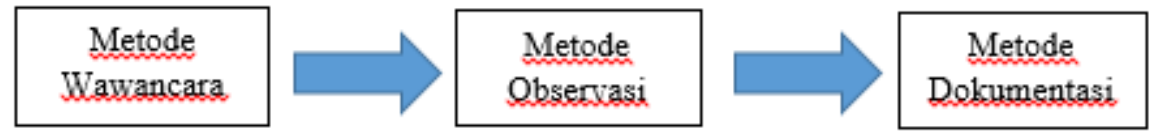

Gambar 1: Metode Pengumpulan Data

\section{HASIL DAN PEMBAHASAN}

Pelaksanaan Supervisi Pendidikan Guru oleh Supervisor di MAN 2 Pangandaran

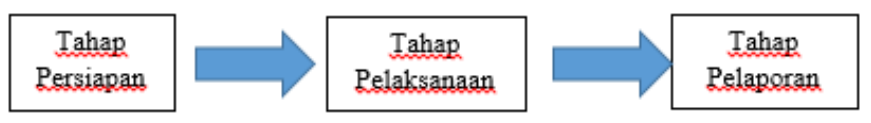

Gambar 2: Tahap Pelakasanaan Supervisi Pendidikan di MAN 2 Pangandaran

Pada tabel 2 dalam pelaksanaannya, secara garis besar pelaksanaan supervise Pendidikan guru di MAN 2 Pangandaran meliputi tiga tahap yaitu tahap persiapan, tahap pelaksanaan dan tahap pelaporan.

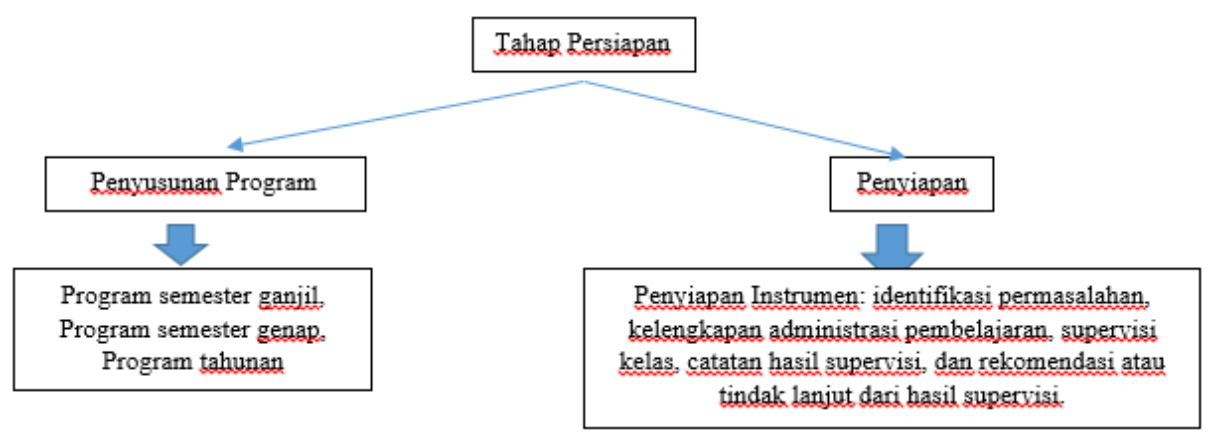

Gambar 3: Tahap Persiapan Pelakasanaan Supervisi Pendidikan di MAN 2 Pangandaran

Ada beberapa instrument yang terpenuhi dalam tahap persiapan yaitu: Silabus, Program Tahunan, Program Semester, Kalender Pendidikan, RPP, Presensi Siswa, Blanko Penetapan KKM, dan Daftar Nilai. Ini semua dilakukan sebagai bentuk persiapan supervisor untuk melangkah ke tahap selanjutnya yaitu supervisi kelas terhadap guru yang sedang melakukan proses pembelajaran dengan menggunakan instrumen yang telah dipersiapkan sebelumnya. 


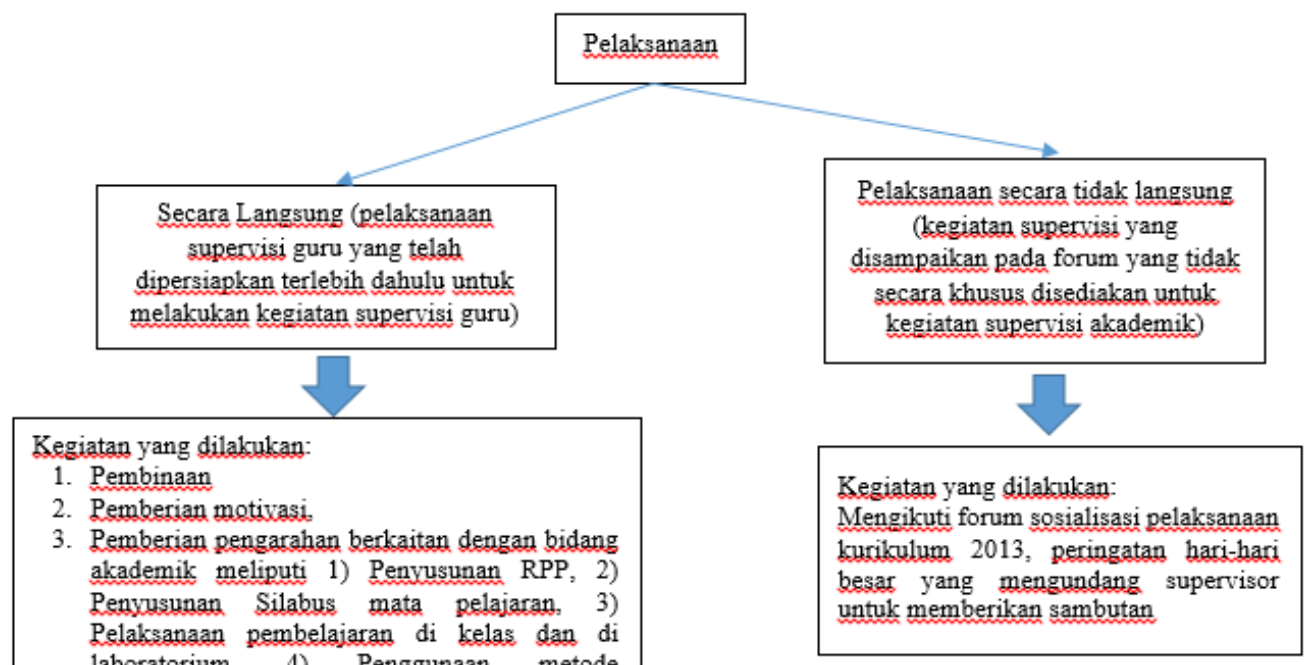

Tahap kedua tentang supervise pembelajaran di MAN 2 Pangandaran adalah tahap pelaksanaan, dalam tahap ini ada menjadi dua pelaksanaan kegiatan supervise pembelajaran yaitu langsung dan tidak langsung.

Kegiatan dalam melakukan pembinaan, pemberian motivasi, dan memberikan pengarahan kepada Guru yang disampaikan diluar kelas bersifat teoritis dan konseptif.

Keberhasilan pelaksanaan supervisi pembelajaran oleh guru di MAN 2 Pangandaran dipengaruhi oleh faktor yaitu:

1) Motivasi kegiatan supervisi pembelajaran guru di MAN 2 Pangandaran cukup tinggi,

2) Pengalaman pengawas guru MAN 2 Pangandaran yang berpengalaman.

3) Dukungan yang tinggi dari MAN 2 Pangandaran dalam pelaksanaan kegiatan supervisi pembelajaran guru oleh pengawas.

Faktor penghambat dalam pelaksanaan supervisi pembelajaran di MAN 2 a. Guru kurang memperhatikan kelengkapan perangkat dalam pembelajaran.

b. Paradigma dan pola pembalajaran yang konvensional ada di MAN 2 Pangandaran sangat sulit untuk dirubah.

c. Belum tersedianya sarana pembelajaran multi media.

d. Semangat guru dalam peningkatan kompetensi cukup rendah.

\section{Kondisi Profesionalisme Guru di MAN 2 Pangandaran}

Secara umum, profesionalisme guru MAN 2 Pangandaran sudah cukup baik.

Permasalahan mendasar yang dihadapi guru MAN 2 Pangandaran yaitu:

a. Kemampuan siswa dalam hal akademik masih rendah

b. Motivasi belajar siswa masih rendah

c. Kemauan dalam mengerjakan tugas masih rendah.

Pangandaran yaitu: 
Analisis data dan Hasil Wawancara

Pelaksanaan supervisi pendidikan guru di MAN 2 Pangandaran sudah baik. Hal ini didukung pada fakta yang ada di dalam keseluruhan proses yang telah dilalui oleh supervisor dalam melakukan kegiatan supervisi pendidikan guru di MAN 2 Pangandaran yaitu:

- Telah terpenuhinya prosedur pelaksanaan supervisi pembelajaran guru.

- Pelaksanaan supervisi pembelajaran mempunyai data yang valid penggunaan instrumen.

- Penggunaan konsep modern dalam pelaksanaan kegiatan supervisi pembelajaran di MAN 2 Pangandaran.

Pelaksanaan kegiatan supervisi pembelajaran sudah baik. Namun, hasil dari pelaksanaan supervisi pembelajaran belum berpengaruh pada meningkatnya profesionalisme guru di MAN 2 Pangandaran.

Program kegiatan supervisi pembelajaran yang telah dilaksanakan belum mampu menunjukkan adanya pengaruh, dampak dan hasil untuk meningkatnya profesionalisme guru di MAN 2 Pangandaran.

Dukungan dari pemimpin sebagai orang yang memiliki tanggung jawab terhadap kinerja guru, harus menjadi perhatian yang lebih serius untuk melakukan langkah agar menciptakan terobosan yang inovatif. Sikap kepekaan dan insiatif yang tinggi pada kebutuhan, mampu beradaptasi akan perubahan zaman, bersifat terbuka dan fleksibel terhadap guru akan mempunyai pengaruh yang besar bagi motivasi para guru untuk mengikuti program yang telah direncankan.

Peran kepala sekolah MAN 2 Pangandaran sebagai supervisor juga masih belum optimal, hasil wawancara yang dilakukan, beliau mengatakan pelaksanaan supervisi pembelajaran biasanya mengikuti jadwal dari Kemenag, sementar pelaksanaan peran kepala sekolah sebagai supervisor masih minim dalam melakukan bimbingan, belum optimalnya peran Kepala Sekolah MAN 2 Pangandaran dalam memberikan penjelasan mengenai prosedur-prosedur pelaksanaan supervisi yang efektif, efisien, serta inovatif. Sehingga ada kesulitan untuk melaksanakan supervisi kepada guru disini.

\section{KESIMPULAN}

Berdasarkan analisis dan pembahasan yang dilaksanakan, maka bisa disimpulkan bahwa:

1. Pelaksanaan supervisi guru oleh supervisor di MAN 2 Pangandaran sudah baik

2. Profesionalisme guru MAN 2 Pangandaran sudah cukup baik.

3. Pelaksanaan supervisi pendidikan guru di MAN 2 Pangandaran memberikan pengaruh yang cukup signifikan untuk meningkatkan profesionalisme guru di MAN 2 Pangandaran.

4. Pelaksanaan supervisi diharapkan dapat meningkatkan profesionalisme guru yang berdampak pada kualitas pembelajaran

5. Kualitas pembelajaran yang baik diharapkan dapat mencapai tujuan pendidikan. 


\section{DAFTAR PUSTAKA}

[1] Mulyana. 2002. Manajemen Berbasis Sekolah, Konsep Strategi daan Implementasi. Bandung: Pt Remaja Rosda Karya.

[2] Ngalim Purwanto. 2010. Adiministrasi dan Supervisi Pendidikan. Bandung: PT Remaja Rosda Karya

[3] Hamzah B Uno, Model Pembelajaran Menciptakan Proses Belajar Mengajar Yang Kreatif dan Efektif. Jakarta: Bumi Aksara, 2017
[4] Suharsimi A, Prosedur Penelitian Suatu Pendekatan Praktik. Jakarta: Rineka Cipta, 2013

[5] Aan Hasanah, Pengembangan Profesi Guru. Bandung: Pustaka Setia, 2012

[6] E. Mulyasa, Standar Kompetensi dan Sertifikasi Guru. Bandung: PT Remaja

[7] http://eprints.walisongo.ac.id/id/eprint/ 4658/1/093111070.pdf 